\title{
All in the Family: Headaches and Abdominal Pain as Indicators for Consultation Patterns in Families
}

\author{
Mieke Cardol, $P b D^{1}$ \\ Wil J.H.M. van den Bosch, MD, \\ $P b D^{2}$ \\ Peter Spreeuwenberg, $M A^{1}$ \\ Peter $P$. Groenewegen, $P b D^{1,3}$ \\ Liset van Dijk, $P b D^{1}$ \\ Dinny H. de Bakker, $P b D^{1}$ \\ 'NIVEL, Utrecht, the Netherlands \\ ${ }^{2}$ Radboud University Nijmegen, Nijmegen, \\ the Netherlands \\ ${ }^{3}$ Department of Sociology and Department \\ of Human Geography, Utrecht University, \\ Utrecht, the Netherlands
}

Conflicts of interest: none reported

\section{CORRESPONDING AUTHOR}

Mieke Cardol, PhD

NIVEL

PO Box 1568

3500 BN Utrecht

Utrecht, the Netherlands

m.cardol@nivel.nl

\begin{abstract}
PURPOSE Headaches and abdominal pain are examples of minor ailments that are generally self-limiting. We examined the extent to which patterns of visits to family physicians for minor ailments, such as headaches or abdominal pain, cluster within families.
\end{abstract}

METHODS Using information from the Second Dutch National Survey of General Practice for 96 family practices, we analyzed the visits of families with at least 1 child aged 12 years or younger during a period of 12 months.

RESULTS Family patterns were clearest in the visits of mothers and children. A large part of the similarity in the frequencies of contact by mothers and daughters could be attributed to shared family factors. This finding was especially true for families with a child who had a headache or abdominal pain as the presenting symptom, rather than physical trauma or chronic disease. Within families, we did not find any specific patterns of diagnoses. Diagnoses were recorded by family physicians. In the case of young children, family similarity may have been overestimated because parents initiated the visits and put their child's health problem into words.

CONCLUSIONS Visits to family physicians for headaches or abdominal pain can be seen as indicators of consultation patterns in families. Family patterns related to minor ailments are likely to be a result of socialization. Family consultation patterns might point toward specific needs of families and consequently at a different approach to treatment.

Ann Fam Med 2006;4:506-511. DOI: 10.1370/afm.584.

\section{INTRODUCTION}

$\mathrm{H}$ eadaches and abdominal pain are examples of minor ailments that often have no identifiable medical cause and that frequently resolve without the need to seek the advice of a physician. These 2 ailments can nonetheless be reasons for parents and their children to consult their family physician. ${ }^{1,2}$ Visits to a family physician for abdominal pain occur primarily for young children, whereas visits related to headaches occur more frequently for older children and adults. ${ }^{3}$ Even young infants are sometimes taken to the physician by their parents for headaches.

Besides factors at the level of the individual, factors at the level of the family can also result in specific consultation patterns within families. Earlier research has indicated similarities between family members in both health and the frequency of contact with the practice that can be traced back to shared family factors. ${ }^{4-17}$ For example, a study of patients frequently visiting a rural practice in the United Kingdom showed that a large proportion of these patients were related by direct or extended family ties. ${ }^{18}$ This knowledge fits into a family-oriented or context-oriented approach in primary care. For family physicians, the context of their patients' lives 
is important in understanding their health complaints. Recognizing family patterns and knowing the family situation can be important for effective transfer of information, prevention, and treatment. ${ }^{9,19,20}$ When patients frequently consult their family physician for minor ailments, this behavior may be a signal for physicians that another approach should be taken. ${ }^{21}$

An empirical model for why family members resemble each other in health and consultation behavior has been published recently. ${ }^{22}$ Similarity in consultation patterns within families can result from similarity in background characteristics, socialization, and shared circumstances. Similarity in background characteristics, for example, can include the genetic transfer of, or susceptibility to, an illness, or the attraction of similar types as marital partners. Socialization refers to learning when to call something an illness and when it requires a visit to a physician. Shared circumstances could include shared physical living environment, life events, or diet, or the transfer of infectious diseases through a shared daily life. We found that socialization processes were the main explanation for family resemblance in frequencies of contact with family physicians. ${ }^{22}$

In this study, we explored how family resemblance differs for various diagnoses and family members. Our starting point was the hypothesis that consultation patterns in families are particularly related to minor ailments, such as headaches or abdominal pain. In the case of minor ailments, family members can choose to visit or to not visit their family physician. In contrast, individuals generally must visit a physician for more serious ailments, such as a fracture or a chronic disorder. We expected that families with children visiting their family physician with a headache, abdominal pain, or other minor ailment would resemble one another more with respect to consultation patterns than families with children that do not visit family physicians with these ailments. In brief, we asked the following questions: (1) do patterns in frequency of visits to family physicians cluster more in families with a child making a visit for minor ailments than in families with a child making a visit for physical trauma or chronic disease? and (2) is there a relationship between the types of symptoms or diagnoses of family members that indicates shared family factors?

\section{METHODS}

\section{Study Population}

We used the registration data of the Second Dutch National Survey of General Practice, which were obtained mainly from electronic medical records. ${ }^{23}$ The demographic characteristics of patients, such as age and sex, were ascertained from a short written questionnaire that was sent to all patients listed with the participating practices. Selection of practices was based on 3 stratification criteria: region, level of urbanization, and practice type (solo or group). The practices included were representative of the Netherlands with respect to region, level of urbanization, and composition of the patient population; solo practices were slightly underrepresented.

Almost all noninstitutionalized Dutch citizens are registered with a family physician, and family members are usually registered with the same one. We studied 96 practices of family physicians. Analyses were based on face-to-face contacts (visits) in these practices between physicians and families who had at least 1 child aged 12 years or younger. Families were defined as a social unit having at least 1 parent and 1 child who together formed a household and who were both listed in the same practice.

\section{Study Measures}

We studied consultation patterns related to the frequency of contacts with the family physician and the symptoms and diagnoses recorded in the electronic medical records. We compared the consultation patterns of individuals in families according to the following 5 clusters of symptoms and diagnoses: (1) headaches (common headache, tension headache); (2) abdominal pain (generalized abdominal pain, localized abdominal pain); (3) other somatic minor ailments (those with symptom codes that refer to such complaints as fatigue, nausea, pain, dizziness, and coughing and sneezing) ${ }^{24}$; (4) musculoskeletal trauma (fractures, strains of the ankle or knee, dislocations); and (5) chronic disease (congenital defects, migraine, asthma, chronic bronchitis, chronic eczema, rheumatoid arthritis, diabetes mellitus, or other chronic illnesses of the digestive tract and other organs). ${ }^{3}$

\section{Analysis}

The dependent variable was the individual contact frequency, defined as the number of face-to-face contacts counted for an individual in a year. Contact frequencies were count data with a skewed distribution; therefore, we used a Poisson regression model to analyze the contact frequencies of individuals in families. ${ }^{25}$ We performed multilevel analysis (MLwiN software, University of Bristol, Bristol, UK) with 3 levels: the family physician's practice, the family, and the individual. ${ }^{26}$ Because we were interested in the influence of the context, we divided contextual variance in contact frequencies into 2 parts: a part that could be attributed to differences between families and a part that indicated differences between practices. In this 
way, we took into account the fact that individual contact frequencies were not independent from the family background and, at the same time, that they cluster within practices. After all, some family physicians will more frequently ask patients to come back than others, while some will discourage contact for minor ailments more than others.

We looked at how family influence leads to more similarity in consultation patterns among family members in 2 ways: by assessing the shared variation in contact frequency at the family level and by assessing correlations in symptoms or diagnoses at the family level. The variation at the family level provides insight into the differences in contact frequency between families. For example, do individual contact frequencies cluster more in families in which children make visits for headaches, abdominal pain, or other minor ailments than in families in which children make visits for musculoskeletal trauma or chronic illness? For this comparison, we selected families on the basis of symptoms or diagnoses for at least 1 child in the family. We divided the shared group variance into parent-child and child-child pairs.

The correlations observed provide insight into the relationships between symptoms or diagnoses of individuals as well as of families. We corrected all analyses for systematic differences related to age and sex, and for clustering of families in practices. In the Supplemental Table, available online-only at http://www. the Poisson model underlying the calculations of the percentage of shared variance is shown to clarify how we performed the analyses.

\section{RESULTS}

Table 1 shows the characteristics of the study population, which included more than 30,000 families: almost 66,000 children and 57,000 parents. The average age of the children was $8-1 / 2$ years. On average, during the study year, families made 2 visits to the family physician for the children and 3 visits for the parents. Among the health complaints we studied, contacts with the family physician for the group of minor ailments were most frequent among the children.

As shown in the Supplemental Table, practice-level factors accounted for only $2 \%$ of the overall contextual variance in individual contact frequencies. The amount of variance attributable to family-level and practicelevel factors differed by diagnostic group. For example, in the group of families with a child making a visit for headache or abdominal pain, the percentage of contextual variance that could be ascribed to the practice level was lower, $1 \%$ and $2 \%$, respectively, than that in the families with a child making a visit for acute trauma
Table 1. Characteristics of the Study Population $(\mathrm{N}=122,601)$

\begin{tabular}{lc}
\hline Characteristic & $\begin{array}{c}\text { Number } \\
\text { or Mean }\end{array}$ \\
\hline Families & 31,309 \\
Number & $3.9(1.1 ; 2-12)$ \\
Mean number of family members (SD; range) & \\
Children & 65,671 \\
Number & \\
Number with $\geq 1$ consultation & 966 \\
$\quad$ Headache & 1,802 \\
Abdominal pain & 15,350 \\
Minor ailments & 7,668 \\
Chronic illnesses & 3,055 \\
$\quad$ Musculoskeletal trauma & $8.5(4.9 ; 1-12)$ \\
Mean age, y (SD; range) & $1.9(2 ; 2.4 ; 0-43)$ \\
Mean consultation frequency* per year & \\
(median; SD; range) & 48.5 \\
Girls, \% & \\
Parents & \\
Number & 56,930 \\
Mean age, y (SD; range) & $38.4(6.3 ; 19-75)$ \\
Mean consultation frequency* per year & $3.0(2 ; 3.7 ; 0-75)$ \\
(median; SD; range) & \\
Women, \% & 53.9 \\
\hline * Number of visits. & \\
\hline
\end{tabular}

or chronic illness, for which the percentage was $4 \%$. In families in which a child visited for a headache or abdominal pain, more variation in contact frequency was attributable to shared family factors. There were more differences between practices when it came to families with a child making a visit for minor ailments in general. In those cases, about $10 \%$ of the variance in individual contact frequencies could be ascribed to practice-level factors.

In Table 2, the variance at the family level is divided into pairs of family members and groups of diagnoses for which the family physician was consulted. As the table shows, there was always a certain amount of family influence, no matter what pair or diagnostic group we studied. As expected, the clustering of contact frequencies on a family level was clearest in the visits of mothers and daughters, but the extent differed between diagnoses. For example, in families with a child making a visit for headache, $48 \%$ of the variation in contact frequency of mothers and daughters was attributable to shared family factors. In families with a child making a visit for abdominal pain, $35 \%$ of the mother-daughter variation was attributable to shared family factors. For parents and sons, the highest percentages of variation in contact frequencies attributable to shared family factors were found in families with a child with abdominal pain: $35 \%$ for 
Table 2. Percentage of Shared Variance in Consultation Frequency Between Families According to Consultation Diagnosis of at Least 1 Child, Corrected for Age, Sex, and Family Practice $(\mathbf{N}=122,601)$

\begin{tabular}{|c|c|c|c|c|c|c|}
\hline \multirow[b]{2}{*}{ Family Members } & \multicolumn{5}{|c|}{ Consultation Diagnosis* } & \multirow[b]{2}{*}{$\begin{array}{c}\text { All Diagnoses } \\
\%\end{array}$} \\
\hline & $\begin{array}{l}\text { Headache } \\
\%(95 \% \mathrm{Cl})\end{array}$ & $\begin{array}{l}\text { Abdominal Pain } \\
\%(95 \% \mathrm{Cl})\end{array}$ & $\begin{array}{l}\text { Minor Ailments } \\
\%(95 \% \mathrm{Cl})\end{array}$ & $\begin{array}{c}\text { Musculoskeletal } \\
\text { Trauma } \\
\%(95 \% \mathrm{Cl}) \\
\end{array}$ & $\begin{array}{c}\text { Chronic Illness } \\
\%(95 \% \mathrm{Cl})\end{array}$ & \\
\hline Mother-father & $\begin{array}{c}12.5 \\
(9.4-16.0)\end{array}$ & $\begin{array}{c}10.0 \\
(7.8-12.3)\end{array}$ & $\begin{array}{c}6.0 \\
(5.3-6.7)\end{array}$ & $\begin{array}{c}10.0 \\
(8.4-11.9)\end{array}$ & $\begin{array}{c}6.7 \\
(5.8-7.7)\end{array}$ & 9.0 \\
\hline Mother-son & $\begin{array}{c}20.2 \\
(16.4-24.1)\end{array}$ & $\begin{array}{c}34.1 \\
(31.0-37.1)\end{array}$ & $\begin{array}{c}19.0 \\
(18.0-20.0)\end{array}$ & $\begin{array}{c}23.8 \\
(21.5-26.1)\end{array}$ & $\begin{array}{c}19.6 \\
(18.2-21.1)\end{array}$ & 21.2 \\
\hline Mother-daughter & $\begin{array}{c}48.4 \\
(44.5-52.3)\end{array}$ & $\begin{array}{c}34.7 \\
(31.7-37.7)\end{array}$ & $\begin{array}{c}23.2 \\
(22.1-24.3)\end{array}$ & $\begin{array}{c}27.8 \\
(25.4-30.1)\end{array}$ & $\begin{array}{c}29.1 \\
(27.6-30.6)\end{array}$ & 24.0 \\
\hline Father-son & $\begin{array}{c}4.7 \\
(2.7-7.2)\end{array}$ & $\begin{array}{c}17.1 \\
(14.4-19.8)\end{array}$ & $\begin{array}{c}8.8 \\
(8.0-9.7)\end{array}$ & $\begin{array}{c}11.2 \\
(9.4-13.1)\end{array}$ & $\begin{array}{c}6.6 \\
(5.6-7.6)\end{array}$ & 10.2 \\
\hline Father-daughter & $\begin{array}{c}14.4 \\
(11.1-18.1)\end{array}$ & $\begin{array}{c}6.9 \\
(5.1-8.9)\end{array}$ & $\begin{array}{c}4.9 \\
(4.3-5.6)\end{array}$ & $\begin{array}{c}7.4 \\
(5.9-9.0)\end{array}$ & $\begin{array}{l}5.2 \\
(4.3-6.1)\end{array}$ & 9.0 \\
\hline Daughter-son & $\begin{array}{c}27.6 \\
(23.5-31.7)\end{array}$ & $\begin{array}{c}26.4 \\
(23.4-29.4)\end{array}$ & $\begin{array}{c}15.1 \\
(14.1-16.1)\end{array}$ & $\begin{array}{c}23.5 \\
(21.3-25.8)\end{array}$ & $\begin{array}{c}18.1 \\
(16.8-19.5)\end{array}$ & 23.0 \\
\hline
\end{tabular}

Note: Shared variance $=$ squared correlation between both family members at family level; $100 \%=$ maximum influence of shared factors at family level, $0 \%=$ no influence of shared family factors.

$\mathrm{Cl}=$ confidence interval.

* The consultation diagnosis was headache for 4,173 families, abdominal pain for 7,414, minor ailments for 50,639, musculoskeletal trauma for 12,644 , and chronic illness for 28,617.

† Based on our previous research on within-family similarity of contact frequencies in family practice. ${ }^{17}$

\section{Table 3. Correlations of Diagnoses in the Study Year, Within Families (Individual Level) and Between Families (Family Level) $(\mathrm{N}=122,601)$}

\begin{tabular}{|c|c|c|c|c|}
\hline Level & $\begin{array}{l}\text { Abdominal } \\
\text { Pain } \\
r\end{array}$ & $\begin{array}{c}\text { Minor } \\
\text { Ailments } \\
r\end{array}$ & $\begin{array}{c}\text { Musculoskeletal } \\
\text { Trauma } \\
r\end{array}$ & $\begin{array}{c}\text { Chronic } \\
\text { Illness } \\
r\end{array}$ \\
\hline \multicolumn{5}{|l|}{ Individual level } \\
\hline Headache & 0.07 & 0.04 & 0.04 & 0.11 \\
\hline Abdominal pain & - & 0.06 & 0.03 & 0.05 \\
\hline Minor ailments & - & - & 0.04 & 0.07 \\
\hline Musculoskeletal trauma & - & - & - & 0.02 \\
\hline \multicolumn{5}{|l|}{ Family level } \\
\hline Headache & 0.38 & 0.28 & 0.18 & 0.47 \\
\hline Abdominal pain & - & 0.43 & 0.18 & 0.23 \\
\hline Minor ailments & - & - & 0.14 & 0.19 \\
\hline Musculoskeletal trauma & - & - & - & 0.04 \\
\hline
\end{tabular}

We evaluated the correlation of symptoms and diagnoses, first among individuals within families and then between families. Table 3 shows that on the individual level, family members, both parents and children, who made visits for headaches during the study year did not often consult the family physician for abdominal pain as well $(r=0.07)$; in fact, all of the correlations were weak on the individual level. As we expected, the correlations on the family level were stronger, in particular, for headache and abdominal pain $(r=0.38)$ and for abdominal pain and minor ailments $(r=0.43)$. mothers and sons and $17 \%$ for fathers and sons. What was strikingly low was the percentage of family-level variation in the contact frequency of fathers and sons in families with a child with headache (5\%).

Contrary to our expectations, the overall percentage of variation attributable to family-level factors in families in which a child visited for minor ailments was lower than that in families in which a child visited for a chronic disease or musculoskeletal trauma. Also, contrary to our expectations, the similarities in contact frequencies between parents, and between siblings, for headaches or abdominal pain were not significantly greater than those for trauma or chronic illness.
Also expected were the weak correlations between visits for headache or abdominal pain and visits for trauma $(r=0.18)$. The correlation between visits for trauma and chronic illness was similarly weak $(r=0.04)$, as anticipated. The correlation between visits of family members for headache and chronic illness was surprisingly strong on the family level, however $(r=0.47)$.

\section{DISCUSSION}

\section{Findings in Relation to Other Literature}

The analysis presented here is the first exploration of family patterns in consultations of family physicians 
that takes into account the hierarchical nature of the data. Family similarity has been studied before, but never before have family patterns been studied in relation to specific relatives in the family and diagnoses resulting from the consultations. Our findings support the hypothesis that visits for headaches or abdominal pain can be seen as indicators of consultation patterns within families. This association becomes especially clear when one looks at the contact frequencies of mothers and children, and to a lesser extent, fathers and children. The much higher percentage of contextual variance at the level of the family as compared with the level of the practice reveals a powerful family-related influence on consultation behavior. In families in which a child makes a visit for headache or abdominal pain, the percentage of variance that can be ascribed to family-level factors is the highest, which means that those families have more similarity in contact frequencies than the other groups of families. For individual consultation behavior, the family context is more influential than the broader context, in this case, the practice. Research into consultation behavior will benefit from adding a family level as a unit of analysis.

Family clustering of visits to family physicians was most pronounced in the contact frequency of mothers and daughters, which is in accordance with earlier research. 9,17,27 Our study also shows the relationship between the consultation patterns of fathers and children, between those of the children themselves, and between those of the parents. The data clearly show that the similarity of consultation frequency within a family varies according to pairs, such as mother and father, or father and son, and also according to specific symptoms or diagnoses for which the family physician is consulted. An unexpected result was that the clustering of consultation behavior within families was not clearly related to minor ailments in general.

Another unexpected result was the strong correlation of visits of family members for headache and chronic disease. Perhaps this finding reflects an association between parents with chronic health complaints and children or partners with headaches. It is known that chronic disease in a family member influences the functioning of the whole family. ${ }^{10}$ Other studies have shown a correlation between anxiety or stress and visits to family physicians. .,6,11 $^{\text {The unhappiness or }}$ discomfort of other family members may be expressed in visits to the family physician for headaches. On the other hand, the strong correlation between headaches and chronic illness might be explained by the fact that we defined migraine as a chronic illness.

Finally, the correlation on a family level between visits for musculoskeletal trauma and visits for chronic disease was strikingly weak. Perhaps in families in which 1 member has a chronic illness, other members are more cautious about their health and safety.

\section{Strengths and Limitations of the Study}

A strength of this study is that we used a large nationally representative data set. A limitation is that the diagnoses were recorded by the family physicians; as a result, the patients' original reasons for visits may have been translated into different diagnoses in the electronic medical record. In addition, in the case of visits of young children, it is often the parents who put their child's problem into words, which may increase similarities in consultation patterns between parents and children.

The unexpected results related to the cluster of minor ailments may have arisen because this cluster was too large and too heterogeneous. As a consequence, families may have no longer been comparable, and the influence of the family may have been underestimated.

\section{Implications for Family Practice}

The results of this study further stress the importance of a context-oriented approach in primary care and show how family patterns of consultation behavior vary according to diagnoses. When physicians recognize a family pattern of consultations for headache or abdominal pain, their response will perhaps not be wait-and-see, as is usual for minor ailments. Instead, they may want to intervene so that the children of parents who visit the family physician too often or too infrequently, in the opinion of the physician, do not later reproduce the consultation pattern of their parents. Of course, in daily practice, individual patients are of primary concern; however, recognizing the contribution of patients' contexts can help point family physicians toward the correct diagnosis or treatment.

The concepts of similarity in background characteristics, socialization, and shared circumstances can serve as a framework for a family case history. The extent to which the observed family clustering can be explained by those 3 concepts is not completely clear from this study. In all likelihood, a visit to the family physician for headache or abdominal pain is partly a result of socialization processes. A strong indicator of this is the large family influence in the contact frequencies of mothers and daughters. ${ }^{22,27}$ In addition, the relationship between the consultation of fathers and mothers shows that family similarities cannot simply be attributed to genetic factors. Especially in the case of minor ailments, patients choose whether to visit the family physician, and learned health behavior influences this choice. Using a context-oriented approach, family physicians might be able to influence consulting behavior that was previously learned within the family. 
Even though the need for a family approach may seem obvious, extra effort and know-how are needed to use a family approach in primary care. ${ }^{28}$ Evidencebased medicine and standards are primarily focused on illnesses and episodes, whereas family medicine is based on continuity of care and requires a different approach. ${ }^{28-31}$ The choice of theory shapes the way people collect and interpret evidence. In general, family physicians often think of families in terms of problem families. ${ }^{32}$ Our study shows, however, that family patterns play a role in all families for all kinds of health complaints.

To read or post commentaries in response to this article, see it online at http://www.annfammed.org/cgi/current/full/4/6/506.

Key words: Family practice; family health; sociology; chronic disease; health behavior; diagnosis

Submitted September 2, 2005; submitted, revised, March 17, 2006; accepted April 3, 2006.

Funding support: This research project was funded by the Netherlands Organization for Health Research and Development (ZonMw).

\section{References}

1. Bandell-Hoekstra IE, Abu-Saad HH, Passchier J, et al. Prevalence and characteristics of headache in Dutch schoolchildren. Eur J Pain. 2001;5:145-153.

2. Van der Linden M, Van Suijlekom-Smit L, Schellevis F, Van der Wouden J. Het Kind in de Huisartspraktijk [The Child in General Practice]. Rotterdam/Utrecht: Huisartsgeneeskunde Erasmus MC/Kindergeneeskunde Erasmus MC, NIVEL; 2005.

3. Van der Linden M, Westert G, De Bakker D, Schellevis F. Klachten en Aandoeningen in de Bevolking en in de Huisartspraktijk [Health Complaints and Disease in the General Population and in General Practice]. Utrecht/Bilthoven: NIVEL/RIVM; 2004.

4. Aromaa M, Sillanpaa M, Rautava $P$, Helenius H. Pain experience of children with headache and their families: a controlled study. Pediatrics. 2000;106:270-275

5. Van den Bosch W. Epidemiologische Aspecten van Morbiditeit bij Kinderen [Epidemiological Aspects of Morbidity in Children]. Nijmegen the Netherlands: Katholieke Universiteit Nijmegen; 1992.

6. Campion PD, Gabriel J. Illness behaviour in mothers with young children. Soc Sci Med. 1985;20:325-330.

7. Carlson M, Corcoran M. Family structure and children's behavioral and cognitive outcomes. J Marriage Fam. 2001;63:779-792.

8. Dowrick C. Why do the O'Sheas consult so often? An exploration of complex family illness behaviour. Soc Sci Med. 1992;34:491-497.

9. Huijgen F. Family Medicine; the Medical Life History of Families. Nijmegen, the Netherlands: Dekker \& Van de Vegt; 1978.

10. Litman TJ. The family as a basic unit in health and medical care: a social-behavioral overview. Soc Sci Med. 1974;8:495-519.
11. Little P, Somerville J, Williamson I, et al. Family influences in a cross-sectional survey of higher child attendance. $\mathrm{Br} J \mathrm{Gen}$ Pract. 2001;51:977-981, 984

12. Starfield B, van den Berg BJ, Steinwachs DM, Katz HP, Horn SD. Variations in utilization of health services by children. Pediatrics. 1979;63:633-641

13. Hippisley-Cox J, Coupland C, Pringle M, Crown N, Hammersley V. Married couples' risk of same disease: cross sectional study. BMJ. 2002;325:636-640

14. Kalmijn M. Intermarriage and homogamy: causes, patterns, trends. Annu Rev Sociol. 1998;24:395-421.

15. Ferrer RL, Palmer R, Burge $\mathrm{S}$. The family contribution to health status: a population-level estimate. Ann Fam Med. 2005;3:102-108.

16. Starfield B, Katz H, Gabriel A, et al. Morbidity in childhood-a longitudinal view. N Engl J Med. 1984;310:824-829.

17. Cardol M, Groenewegen PP, de Bakker DH, et al. Shared help seeking behaviour within families: a retrospective cohort study. BMJ. 2005;330:882-885

18. Stewart $P, O^{\prime}$ Dowd T. Clinically inexplicable frequent attenders in general practice. Br J Gen Pract. 2002;52:1000-1001.

19. Cole-Kelly K, Seaburn D. Five areas of questioning to promote a family-oriented approach in primary care. Fam Systems Health. 1999;17:341-348

20. van den Bosch WJ, Huygen FJ, van den Hoogen HJ, van Weel C. Morbidity in early childhood: family patterns in relation to sex, birth order, and social class. Fam Med. 1993;25:126-130.

21. Morris CJ, Cantrill JA, Weiss MC. GPs' attitudes to minor ailments. Fam Pract. 2001;18:581-585.

22. Cardol M, Groenewegen P, Spreeuwenberg P, et al. Why does it run in families? Explaining help-seeking behaviour by shared circumstances, socialisation and selection. Soc Sci Med 2006;63:920-932.

23. Westert GP, Schellevis FG, de Bakker DH, et al. Monitoring health inequalities through general practice: the Second Dutch National Survey of General Practice. Eur J Public Health. 2005;15:59-65.

24. Barsky AJ, Borus JF. Functional somatic syndromes. Ann Intern Med. 1999;130:910-921.

25. Snijders T, Bosker R. Multilevel Analysis: An Introduction to Basic and Advanced Multilevel Modeling. London, England: Sage Publications; 1999.

26. Leyland $A H$, Groenewegen PP. Multilevel modeling and public health policy. Scand J Public Health. 2003;31:267-274.

27. Mechanic D. The influence of mothers on their children's health attitudes and behavior. Pediatrics. 1964;33:444-453.

28. Launer J, Lindsey C. Training for systemic general practice: a new approach from the Tavistock Clinic. Br J Gen Pract. 1997;47:453-456.

29. Safran DG. Defining the future of primary care: what can we learn from patients? Ann Intern Med. 2003;138:248-255.

30. Saultz JW. Reflections on internal medicine and family medicine. Ann Intern Med. 1996;124:600-603.

31. Campbell T, Culpepper L. Family medicine. In: Jones R, Britten N Culpepper $\mathrm{L}$, et al, eds. Oxford Textbook of Primary Medical Care. Oxford, England: Oxford University Press; 2004:299-309.

32. Levine C, Zuckerman C. The trouble with families: toward an ethic of accommodation. Ann Intern Med. 1999;130:148-152. 